\title{
"Echocardiography in Nigeria: use, problems, reproducibility and potentials"
}

\author{
Okechukwu S Ogah*1, Ademola T Adebanjo ${ }^{1}$, Adedeji S Otukoya ${ }^{1}$ and \\ Tarwanger J Jagusa ${ }^{2}$
} \author{
Medical Centre, Idi-Aba, PMB 3031 Abeokuta, Nigeria \\ Email: Okechukwu S Ogah* - osogah56156@yahoo.com; Ademola T Adebanjo - demolaadebanjo@yahoo.com; \\ Adedeji S Otukoya - dejiotukoya@yahoo.com; Tarwanger J Jagusa - drjagusa@yahoo.com \\ * Corresponding author
}

Address: ${ }^{1}$ Department of Medicine, Federal Medical Centre, Idi-Aba, PMB 3031 Abeokuta, Nigeria and ${ }^{2}$ Department of Family Medicine, Federal

Published: 21 March 2006

Cardiovascular Ultrasound2006, 4:13 doi:10.1186/1476-7/20-4-13
Received: 14 January 2006

Accepted: 21 March 2006

This article is available from: http://www.cardiovascularultrasound.com/content/4/I//3

(c) 2006Ogah et al; licensee BioMed Central Ltd.

This is an Open Access article distributed under the terms of the Creative Commons Attribution License (http://creativecommons.org/licenses/by/2.0), which permits unrestricted use, distribution, and reproduction in any medium, provided the original work is properly cited.

\begin{abstract}
Background: Although echocardiography is a useful and cost-effective technique for the detection of morphological and functional cardiac abnormalities, it has a main limitation in its subjectivity. Therefore the aim of the present study was to assess the intra-observer reproducibility and validity of 2-dimensional guided M-mode echo measurements at a Nigerian metropolitan Hospital
\end{abstract}

Methods: Standard echocardiographic examination was performed on twenty randomly selected patients (II men and 9 women) aged $59.8 \pm 12.6$ years in two different sessions seven days apart.

Results: A good degree of intraobserver agreement was observed between test I and test 2 . The correlation coefficient between the first and second studies ranged between 0.60 and 0.96 ; measurement errors between 0.050 and 0.205 .

Conclusion: We would conclude that 2-dimensional guided M-mode measurements at echocardiography performed at our centre are reproducible with low intra-observer variability.

\section{Background}

Echocardiography came into use in Nigeria in the mid 70 's, however, in very few centres mostly concentrated in urban areas. Accessibility to echocardiography in Nigeria is still very low due to the high costs of the technique and to the lack of highly specialized personnel performing it. In fact, the country has less than fifty cardiologists serving a population of over 120 million inhabitants. Training in echocardiography is part of the postgraduate residency training requirements in cardiology in Nigeria.

The country, like most developing nations does not have an accreditation process as those designed in Europe and the United States. Separate proficiency examinations in echocardiography such as the British Society of echocardiography examination or similar examination recently introduced by the European Society of Echocardiography are not available. Nevertheless, some of the cardiologists had part or all of their clinical training in advanced countries.

Echocardiography is a highly subjective technique that requires a standardized approach due to its proven clinical usefulness. 
Therefore, the aim of our study was to assess the intraobserver variability in M-mode echocardiographic measurements in an urban hospital and to provide a picture of the main indications to an echo exam in Nigeria. This type of survey was never addressed before. We therefore, assessed the intraobserver variability in echocardiographic measurement in our centre.

\section{Methods}

The study was carried out at the Department of Medicine, Federal Medical Centre, Abeokuta, Nigeria between September and November 2005. The centre is a relatively young tertiary institution, established in 1993 by the Federal Government of Nigeria to cater for the health need of the people of Ogun State in South-western Nigeria. The state has a population of about 3.2 million and a land area of about 16,409.26 square kilometres.

Echocardiography is performed at our centre on a weekly basis except in emergency situations. An average of ten echocardiograms is performed per week.

During the period of the study, a total of one hundred and four subjects had echocardiogram. The main indications for echocardiography were hypertensive heart disease, congestive cardiac failure, heart murmur and pre-operative evaluation of cardiac function. Twenty-three of the subjects were randomly selected for the study. (with the use of computer generated random numbers) Two of the subjects had poor 'echo' window and one had regional wall motion abnormality due to left bundle branch block and were therefore excluded. All the other twenty subjects had symmetrically contracting left ventricles.

Informed consent was obtained from the subjects and ethical approval was obtained from our institution's ethical review committee.

\section{Clinical evaluation}

Baseline clinical and demographic characteristics were obtained from the subjects. These included date of birth, age, gender and indication for echocardiogram.

Blood pressure measurements were obtained according to standard guidelines [1] with a mercury sphygmomanometer (Accosson London). Systolic and diastolic blood pressures were measured at Korotkoff sounds phase I and V respectively. Blood pressure was measured at the right arm three times after a 5 minutes rest. Blood pressure 140/90 and above was taken as hypertension. Subjects were weighed without shoes and in light clothing on a standard beam balance. Height was measured to the nearest centimetre using anthropometrical plane with subjects not putting on shoes or headgear.
Body mass index (BMI) was calculated using the formula: BMI $=$ Weight $(\mathrm{kg}) /$ Height $^{2}\left(\mathrm{~m}^{2}\right)$. Body surface area (BSA) was calculated using the formula of Dubois [2].

\section{Echocardiography}

Two-dimensional guided M-mode echocardiography with the use of commercially available echo-machine (ALOKA SSD-1, 100) and a $3.5 \mathrm{MHz}$ linear array transducer was performed on each subject in the partial decubitus position. All measurements were made according to the American Society of Echocardiography (ASE) leading edge to leading edge convention [3]. LV measurement was obtained at end diastole and end systole in the parasternal long axis view. The LV measurements taken include right ventricular outflow tract diameter (RVOT), aortic root diameter (AO), and aortic valve opening (AVO) and left atrial diameter (LA). Others include interventricular septal thickness at end-diastole (IVSTd) and end-systole (IVSTs), the posterior wall thickness at end diastole (PWTd) and end-systole (PWTs), and the LV internal dimensions at end systole (LVIDs) and end diastole (LVIDd). The end of diastole was taken as the peak of the R-wave of the ECG tracing on the echocardiograph while the end-systolic measurements were taken at the nadir of the LV septal wall [3].

LV mass was calculated from the ASE measurements using the cubed formula [4]:

LV mass $(\mathrm{g})=0.8 \times\left\{1.04 \times\left[(\text { IVSTd }+ \text { LVIDd }+ \text { PWTd })^{3}-\right.\right.$ $\left.\left.(\text { LVIDd })^{3}\right]\right\}+0.6$

All the measurements were taken at baseline and one week after. Measurements were taken online and in three cardiac cycles and average of the three values calculated. Off-line measurements were not possible because of the lack of the software in our centre. Image storage was with the use of videotapes. One experienced cardiologist performed all the echocardiography.

Table I: Baseline characteristics of the subjects

$\begin{array}{cc}\text { Age } & 59.8(12.6) \\ \text { Gender (Male/Female) } & 1 \mathrm{I} / 9(55 \% / 45 \%) \\ \text { Weight }(\mathrm{Kg}) & 73(19.3) \\ \text { Height }(\mathrm{cm}) & 161.5(9.4) \\ \text { Body Mass Index }\left(\mathrm{Kg} / \mathrm{m}^{2}\right) & 28.2(6.9) \\ \text { Body Surface Area }\left(\mathrm{m}^{2}\right) & 1.77(0.25) \\ \text { Systolic Blood Pressure }(\mathrm{mmHg}) & 139.4(26.6) \\ \text { Diastolic Blood Pressure }(\mathrm{mmHg}) & 84.7(16.5) \\ \text { Heart Rate (beats/min) } & 85.6(12.9) \\ \text { Indication for Echocardiography } & \\ \text { • Hypertensive Heart Disease } & 16(80 \%) \\ \text { • Rheumatic Heart Disease } & 2(10 \%) \\ \text { - Dilated Cardiomyopathy } & 2(10 \%)\end{array}$




\section{Data analysis}

Data management and analysis were performed with SPSS software version 11.0. (SPSS, Inc. Chicago, Illinois). Continuous variables were expressed as mean \pm SD (standard deviation) and categorical variables expressed as percentages. The paired student t-tests was used to compare the means of baseline and repeated measures. Differences between the repeated measures (measurement 1 minus measurement 2) were plotted against the mean of repeated measures (measurement 1 plus measurement 2 divided by 2) according to the method of Bland and Alt$\operatorname{man}[5]$

A 2-tailed p value $<0.05$ was considered to be significant.

\section{Results}

Table1 shows the baseline clinical and demographic characteristics of the subjects. The study subjects were made up of eleven men and nine women constituting 55\% and $45 \%$ respectively. The mean age was $59.8 \pm 12.6$ years (range 39-76 years).

The mean body mass index was $28.2 \pm 6.9 \mathrm{~kg} / \mathrm{m}^{2}$ while mean body surface area was $1.77 \pm 0.25 \mathrm{~m}^{2}$. Mean systolic blood pressure, diastolic blood pressure and pulse rate were $139.4 \pm 26.6 \mathrm{mmHg}, 84.7 \pm 16.5 \mathrm{mmHg}$ and $85.6 \pm$ 12.9 beats/min respectively.

The indications for echocardiography were hypertensive heart disease (sixteen subjects), rheumatic heart disease

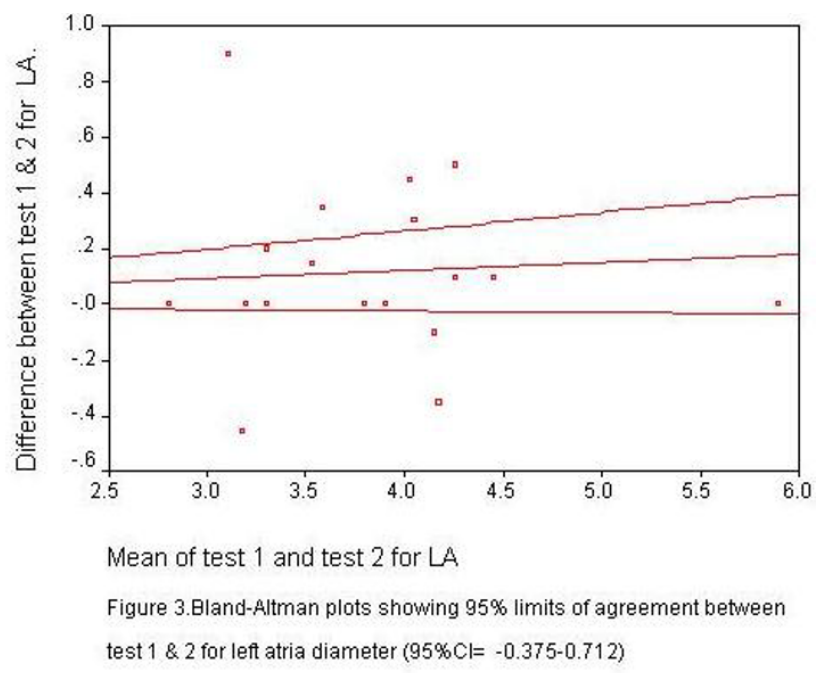

Figure I

Bland-Altman plots showing $95 \%$ limits of agreement between test I and 2 for left atrial diameter $(95 \% \mathrm{Cl}=-0.375-$ 0.712 ) (two subjects) and dilated cardiomyopathy (two subjects).

Echocardiographic diagnosis made were hypertensive heart disease (left ventricular hypertrophy and/or diastolic dysfunction) in ten of the sixteen hypertensives, and normal study in the remaining six subjects. Mixed mitral valve disease (but predominantly mitral stenosis) was diagnosed in the two female subjects with rheumatic heart disease.

The dilated cardiomyopathy cases were pregnancy related (peripartal cardiomyopathy) which is a common disorder in Nigeria especially in northern Nigeria, which is reported to have the highest incidence in the world.

Scatter plots of LV measurements were performed for measurements 1 and 2 (plots not shown) Bland - Altman plots were also performed to determine the 95\% confidence limits of agreement between the two measurements. Two of such plots are shown in figures 1 and 2 .

The plots provided visual information on the degree of disagreement, as well as the relationship of the differences and size of the measurements. Most of the plots were near the zero- difference line and showed uniform distribution pattern.

Table 2 displays the degree of correlation between the first and second measurements as well as the 95\% confidence intervals. There was good correlation between the two measurements in all the parameters. The intraobserver concordance correlation coefficient for RVOT, aortic root

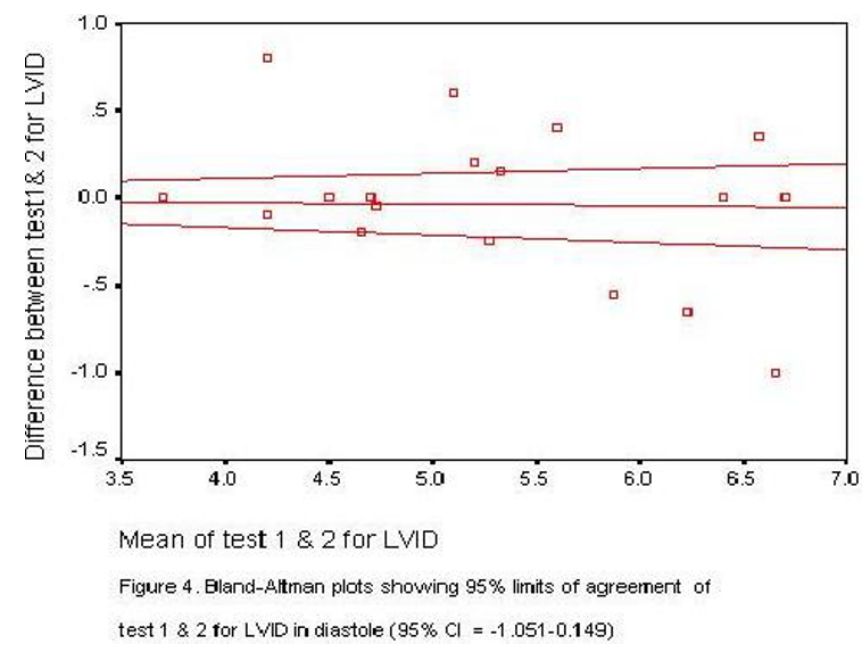

Figure 2

Bland-Altman plots showing $95 \%$ limits of agreement between test I and test 2 for LVID in diastole $(95 \% \mathrm{CI}=$ I.05I-0.|49) 
Table 2: Correlation between the two measurements

\begin{tabular}{|c|c|c|c|}
\hline PARAMETER & $\mathbf{r}$ & $\mathbf{P}$ & $95 \% \mathrm{Cl}$ \\
\hline RVOT & 0.76 & $<0.0001$ & $0.470-898$ \\
\hline $\mathrm{AO}$ & 0.91 & $<0.0001$ & $0.787-0.965$ \\
\hline AVO & 0.60 & $0.004 I$ & $0.217-0.825$ \\
\hline LA & 0.91 & $<0.0001$ & $0.789-0.970$ \\
\hline IVSD & 0.93 & $<0.0001$ & $0.835-0.933$ \\
\hline IVSS & 0.81 & $<0.0001$ & $0.566-0.920$ \\
\hline LVID & 0.92 & $<0.0001$ & $0.795-0.967$ \\
\hline LVIS & 0.96 & $<0.0001$ & $0.90-0.98$ \\
\hline PWTd & 0.75 & $<0.0001$ & $0.453-0.894$ \\
\hline PWTs & 0.79 & $<0.0001$ & $0.526-0.911$ \\
\hline LVM & 0.89 & $<0.0001$ & $0.748-0.958$ \\
\hline
\end{tabular}

RVOT = Right Ventricular Outflow Diameter, AO = Aortic Root Diameter, AVO = Aortic Valve Opening, LA = Left Atrial Diameter, IVSd = Interventricular Septal wall thickness in diastole, IVSs = Interventricular septal wall thickness in systole, LVIDs = Left ventricular Internal Diameter in Diastole, LVIS = Left Ventricular internal diameter in Systole, PWTd = Posterior Wall Thickness in Diastole, PWTs = Posterior Wall Thickness in Systole, LVM = Left Ventricular Mass

diameter, aortic valve separation, left atrial diameter, IVSd, IVSs, LVID, LVIS, PWTd PWTs and LVM were 0.76, $0.91,0.60,0.91,0.93,0.81,0.92,0.96,0.75,0.79$ and 0.89 respectively.

Table 3 depicts the intraobserver comparisons. Difference between first and second measurement of interventricular septal wall thickness in diastole was statistically significant.

Large standard deviations of the difference were found for end diastolic LV diameter, right ventricular outflow tract diameter, aortic root diameter, aortic valve opening and LVM.

\section{Discussion}

Echocardiography is becoming a common practice in Nigeria especially in the major cities. Conventional echocardiographs are commoner. Portable echo-machine is probably available in only one centre. Transoesophageal echocardiography is yet to be introduced into the country. Measurements are obtained on-line in all the centres due to the high cost of off-line software and machines. Recording is mainly by videotapes.

The common indications for echocardiography in Nigeria are hypertensive heart disease, cardiomyopathies, and valvular heart disease.

In a report by Balogun et al[6], hypertensive heart disease, cardiomyopathies, normal echocardiogram, valvular heart disease and pericardial diseases constituted 53\%, $21 \%, 13 \%, 7 \%$, and $4 \%$ respectively of echocardiographic diagnoses in their series. An audit of 1544 echocardiograms performed over a 19-month period (article in press) showed that hypertensive heart disease (51.8\%),

Table 3: Intraobserver comparison of Echocardiographic variables using paired t Test

\begin{tabular}{|c|c|c|c|c|c|}
\hline PARAMETER & $\mathrm{n}$ & TEST I (SD) & TEST 2 (2D) & $\begin{array}{l}\text { MEAN DIFFERENCE } \\
(2 \mathrm{D})\end{array}$ & P VALUE \\
\hline RVOT & 20 & $2.95(0.58)$ & $2.99(0.53)$ & $-0.06(0.39)$ & 0.534 \\
\hline $\mathrm{AO}$ & 20 & $2.74(0.36)$ & $2.77(0.36)$ & $-0.025(0.152)$ & 0.470 \\
\hline AVO & 20 & $1.86(0.46)$ & $1.94(0.35)$ & $-0.08(0.37)$ & 0.365 \\
\hline LA & 20 & $3.89(0.69)$ & $3.76(0.71)$ & $0.12(0.29)$ & 0.078 \\
\hline IVSd & 20 & $1.02(0.27)$ & $0.93(0.25)$ & $0.09(0.10)$ & 0.001 \\
\hline IVSs & 20 & $1.26(0.36)$ & I.22(0.34) & $0.04(0.22)$ & 0.450 \\
\hline LVIDd & 20 & $5.33(0.88)$ & $5.35(1.08)$ & $0.02(0.4 I)$ & 0.850 \\
\hline LVIDs & 20 & $3.80(1.08)$ & $3.83(1.24)$ & $0.03(0.37)$ & 0.744 \\
\hline PWTd & 20 & $1.08(0.20)$ & $1.10(0.23)$ & $0.03(0.16)$ & 0.744 \\
\hline PWTs & 20 & $1.46(0.25)$ & $1.56(0.29)$ & $0.10(0.18)$ & 0.575 \\
\hline LVM & 20 & $217.5(70.2)$ & $211.8(81.0)$ & $5.68(36.3)$ & 0.492 \\
\hline
\end{tabular}

RVOT = Right Ventricular Outflow Diameter, AO = Aortic Root Diameter, AVO = Aortic Valve Opening, LA = Left Atrial Diameter, IVSd = Interventricular Septal wall thickness in diastole, IVSs = Interventricular septal wall thickness in systole, LVIDs = Left ventricular Internal Diameter in Diastole, LVIS = Left Ventricular internal diameter in Systole, PWTd = Posterior Wall Thickness in Diastole, PWTs = Posterior Wall Thickness in Systole, LVM = Left Ventricular Mass 
Table 4: Published studies and Present study: Intraobserver Comparison of Echocardiographic Measurements

\begin{tabular}{ccccccccccccc}
\hline \multicolumn{4}{c}{ Dai et al (ref 27) } & \multicolumn{4}{c}{ Present Study } & \multicolumn{3}{c}{ Ladipo et al (ref 29) } & \multicolumn{3}{c}{ Schieken et al (ref 26) } \\
\hline Parameter & Mdiff & SD & Error & Mdiff & SD & Error & Mdiff & SD & Error & Mdiff & SD & Error \\
RVOT & NA & NA & NA & -0.06 & 0.39 & 0.195 & NA & NA & NA & NA & NA & NA \\
AO & 0.05 & 1.20 & 0.60 & 0.025 & 0.152 & 0.076 & NA & NA & NA & NA & NA & 0.05 \\
AVO & NA & NA & NA & -0.08 & 0.37 & 0.185 & NA & NA & NA & NA & NA & NA \\
LA & 0.15 & 1.35 & 0.675 & 0.12 & 0.29 & 0.145 & NA & NA & NA & NA & NA & 0.06 \\
IVSd & 0.05 & 0.82 & 0.41 & 0.09 & 0.10 & 0.05 & $0.04-0.08$ & $0.06-0.18$ & $0.03-0.09$ & NA & NA & 0.06 \\
IVSs & 0.05 & 1.13 & 0.565 & 0.04 & 0.22 & 0.11 & NA & NA & NA & NA & NA & NA \\
LVIDd & -0.60 & 0.97 & 0.485 & 0.02 & 0.41 & 0.205 & $0.07-0.12$ & $0.10-0.28$ & $0.05-0.14$ & NA & NA & 0.13 \\
LVIDs & -0.15 & 1.18 & 0.595 & 0.03 & 0.37 & 0.185 & $0.02-0.08$ & $0.09-0.20$ & $0.05-0.10$ & NA & NA & 0.10 \\
PWTd & 0.13 & 0.84 & 0.42 & 0.03 & 0.16 & 0.080 & $0.06-0.10$ & $0.09-0.27$ & $0.05-0.14$ & NA & NA & 0.06 \\
PWTs & 0.33 & 1.14 & 0.57 & 0.10 & 0.18 & 0.090 & NA & NA & NA & NA & NA & NA \\
LVM & -1.82 & 18.79 & 9.40 & 5.68 & 36.3 & 18.1 & NA & NA & NA & NA & NA & NA
\end{tabular}

RVOT $=$ Right Ventricular Outflow Diameter, AO = Aortic Root Diameter, AVO = Aortic Valve Opening, LA = Left Atrial Diameter, IVSd $=$ Interventricular Septal wall thickness in diastole, IVSs = Interventricular septal wall thickness in systole, LVIDs = Left ventricular Internal Diameter in Diastole, LVIS = Left Ventricular internal diameter in Systole, PWTd = Posterior Wall Thickness in Diastole, PWTs = Posterior Wall Thickness in Systole, LVM = Left Ventricular Mass, Mdiff = Mean difference, SD = Standard Deviation, Error = SD $/ 2$ NA = Not Available.

normal study (36.5\%), valvular heart disease $(3.5 \%)$, dilated cardiomyopathy $(1.9 \%)$ were the most frequent diagnoses.

The potential of echocardiography as a research tool in Nigeria cannot be overemphasized. Studies emanating from the country have focused on the common cardiovascular diseases in the country such as hypertensive heart disease [7-15], heart failure[16,17], dilated cardiomyopathy including peripartal heart disease, and valvular heart disease $[18,19]$. Others have also studied cardiac function in diabetes mellitus[20-22], congenital heart diseases[23] and sickle cell disease[24]. The usefulness of ECG criteria for the diagnosis of left ventricular hypertrophy in Nigerians using echocardiography as standard has also been reported [25].

This quality assessment study addressed the intraobserver variation of 2-dimensional guided M-mode echocardiographic measurements in our centre. The study demonstrated that echocardiographic measurements by a single cardiologist is consistent and has acceptable intraobserver variation. Interobserver variation was not evaluated in this study because only one cardiologist performs the procedure in our hospital.

Results from other studies on intraobserver variations of echocardiographic measurements vary in study design and method of analyses.

Schieken et al [26] studied the intraobserver variability of aortic root diameter, left atria diameter, LV septal and posterior wall thickness, LV interval dimensions and ejection time in 20 healthy children aged $6-16$ years. The measurement errors (standard deviation divided by 2) were reported as $0.5,0.6,0.6,1.3,0.6,1.0 \mathrm{~mm}$ and 0.01 second respectively. These are comparable to the findings in this study (Table 3). Our measurement errors were 0.195 , $0.076,0.185,0.145,0.050,0.110,0.202,0.185,0.080$, and 0.090 for RVOT, aortic root diameter, aortic root separation, left atrial diameter, IVSd, IVSs, LVID, LVIS, PWTD, and PWTs respectively. Our finding is similar to the observation of Dai et al[27]. Valdez et al[28] reported significant intraobserver difference in only one person in the measurement of LV end diastolic posterior wall diameter in his study of 20 subjects. In the present study significant intraobserver difference was observed only in $\mathrm{LV}$ septal wall thickness in diastole (LVIDd).

In the study by Ladipo et al [29], intraobserver variations were assessed in 10 subjects. The mean difference of $0.7-$ $1.2,0.2-0.8,0.3-0.4$ and $0.4-0.8 \mathrm{~mm}$ were reported for LV internal dimensions in diastole and systole, LV posterior wall thickness in diastole, LV septal wall thickness in diastole respectively. Table 4 shows a summary of previous studies and present study.

The main limitation of echocardiography is its subjectivity in the face of a proven clinical usefulness. Training and accreditation procedures are key factors to obtain a reliable and standard examination. The results of our study demonstrate that when the same person with an appropriate training performs echocardiography, the intraobserver variability is low. This assessment is important in order to have an internal control for our laboratory since this technology might represent the only possible procedure for any given clinical condition. Our data are consistent with previous reports.

Workers have highlighted the sources of variation in echocardiographic measurements[30-32]. These include factors that affect image quality such as subject's body 
build, respiratory status and co-operation. Others include ability of the sonographer to correctly recognize image signals, transducer orientation and placement as well as his/her familiarity with the machine.

\section{Limitations of the study}

Interobserver variability was not analyzed in the present study since echocardiography is performed at our center by only one cardiologist. In Nigeria as previously stated, the number of cardiologists is very small. Nonetheless this analysis and results were aimed at providing an objective assessment of the quality of our laboratory. Furthermore, Doppler measurements were not evaluated. We also did not obtain measurement using the 2D technique, which has been shown to have better reliability than the Mmode technique

\section{Conclusion}

We would conclude that quantitative 2-dimensional guided M-mode echocardiography performed in our centre is reproducible and has good validity. It therefore provides a valuable tool for cardiac structure and function studies.

\section{Competing interests}

The authors declare that they have no competing interests.

\section{Authors' contributions}

OSO conceived of the study, carried out the echocardiograms, analysed the data and drafted the manuscript.

AAT, OAS and JJT participated in the recruitment of subjects and in data management. All authors read and approved the final manuscript

\section{References}

I. American Society of Hypertension : Recommendations for routine blood pressure measurement by indirect cuff sphygmomanometer. Am J Hypertens 1992, 5:207-209.

2. Dubois D, Dubois EF: A formula to estimate the approximate surface area if height and weight be known. Arch Intern Med | 916, | 7:863-87|.

3. Sahn DJ, DeMaria A, Kisslo J, Weyman A: Recommendations regarding Quantitation in M-mode Echocardiography. Results of a survey of Echocardiographic measurements. Circulation 1978, 56:1072-1083.

4. Devereux RB, Alonso DR, Lutas EM, Gottlieb GJ, Campo E, Sachs I, Reichek N: Echocardiographic assessment of left ventricular hypertrophy:comparison to necropsy findings. Am J Cardiol I 986, 57:450-458.

5. Bland JM, Altman DG: Statistical methods for assessing agreement between two methods of clinical measurement. Lancet 1986, I:307-310.

6. Balogun MO, Urhoghide GE, Ukoh VA, Adebayo RA: A preliminary Audit of two dimensional and Doppler Echocardiographic Service in a Nigerian Tertiary Private Hospital. Nig J Med 1999, 8:|39-|4|.

7. Ajayi AA, Akintomide AO, Babalola RO, Akinwusi O: Disproportionate intraventricular septal hypertrophy in Nigerians with essential hypertension. Afr J Med Med Sci 1995, 24:93-96.

8. Ajayi AA, Akinwusi PO: Spectrum of hypertensive heart disease in Nigerians: cross-sectional study of echocardiographic indi- ces and their correlation with treadmill exercise capacity. J Hypertens 1993, I I:99-102.

9. Aje A, Adebiyi AA, Oladapo O, Dada A, Ogah OS, Ojji DB, Falase AO: Left Ventricular Geometric Patterns in Newly presenting Nigerian Hypertensives: An Echocardiographic Study. BMC Cardiovascular Disorders 2006, 6:4.

10. Adebiyi AA, Aje A, Ogah OS, Ojji DB, Dada A, Oladapo O, Falase AO: Correlates of left atrial size in Nigerian hypertensives. Cardiovasc J South Afr 2005, 16:158-16I.

II. Adebiyi AA, Aje A, Ogah OS, Ojji DB, Oladapo O, AO F: Left Ventricular Diastolic Function Parameters in Hypertensives. Journal of the National Medical Association 2005, 97: 1-5.

12. Ike SO, Onwubere BJ: The relationship between diastolic dysfunction and level of blood pressure in Blacks. Ethn Dis 2003, 1 3:463-469.

13. Ogah OS, Adebiyi AA, Oladapo OO, Aje A, Ojji DB, Adebayo AK, Salako BL, Falase AO: Association between Electrocardiographic Left Ventricular Hypertrophy with Strain Pattern and Left Ventricular Structure and Function. Cardiology 2006, 106:|4-2|.

14. Adesanya CO, Sanderson JE, Verheijen PJ, Brinkman AW: Echocardiographic assessment and systolic time interval measurements in the evaluation of severe hypertension in Nigerian Africans. Aust N ZJ Med 198I, I I:364-369.

I5. Babalola RO, Ajayi AA: A cross-sectional study of echocardiographic indices, treadmill exercise capacity and microvascular complications in Nigerian patients with hypertension associated with diabetes mellitus. Diabet Med 1992, 9:899-903.

16. Ajayi AA, Balogun MO, Ajayi AT: Correlation among radiologic, echocardiographic indices and self paced-exercise capacity in heart failure. Int J Cardiol I990, 27:। 35-I37.

17. Oyati IA, Danbauchi SS, Alhassan MA, Isa MS: Diastolic dysfunction in persons with hypertensive heart failure. J Natl Med Assoc 2004, 96:968-973.

18. Jaiyesimi F, Antia AU: Childhood rheumatic heart disease in Nigeria. Trop Geogr Med 1981, 33:8-I3.

19. Adesanya CO: M-mode echocardiography in the diagnosis of mitral stenosis. Niger Med J 1979, 9:533-537.

20. Famuyiwa OO, Odia OJ, Osotimehin BO, Adenle AD, Falase AO: Non-invasive cardiac study in diabetic Nigerians using systolic time intervals. Trop Geogr Med 1985, 37:|43-|49.

21. Osunkwo DA, Okeahialam BN: Left ventricular function in Nigerian Africans with Non-insulin dependent Diabetes Mellitus. Am J Cardiol 2001, 87: 1026-1028.

22. Danbauchi SS, Anumah FE, Alhassan MA, David SO, Onyemelukwe GC, Oyati IA: Left ventricular function in type $\mathbf{2}$ diabetes patients without cardiac symptoms in Zaria, Nigeria. Ethn Dis 2005, 1 5:635-640.

23. Jaiyesimi F, Antia AU: Congenital heart disease in Nigeria: a tenyear experience at UCH, Ibadan. Ann Trop Paediatr 198I, I:77-85.

24. Adebiyi AA, Falase AO, Akenova YA: Left ventricular systolic function of Nigerians with sickle cell anaemia. Tropical Cardiology 1999, 25:27-32.

25. Nkado RN, Onwubere BJ, Ikeh VO, Anisiuba BC: Correlation of electrocardiogram with echocardiographic left ventricular mass in adult Nigerians with systemic hypertension. West Afr J Med 2003, 22:246-249.

26. Schieken RM, Clarke WR, Mahoney LT, Lauer RM: Measurement criteria for group echocardiographic studies. Am J Epidemiol 1979, I | 0:504-514.

27. Dai S, Ayres NA, Harrist RB, Bricker JT, Labarthe DR: Validity of Echocardiographic Measurements in an Epidemiological Study: Project HeartBeat! Hypertension 1999, 34:236-24I.

28. Valdez RS, Motta JA, London E, Martin RP, Haskel WL, Farquhar JW, Popp RL, Horlick L: Evaluation of echocardiogram as an epidemiologic too in an asymptomatic population. Circulation 1979, 60:921-929.

29. Ladipo GIA, Dunn FG, Pringle TH, Bastian B, Lawrie TDV: Serial measurements of left ventricular dimensions by echocardiography: assessment of week-to-week inter- and intraobserver variability in normal subjects and patients with valvular heart disease. Br Heart J I 980, 44:284-289.

30. Devereuex RB, Liebson PR, Horan MJ: Recommendations concerning the use of echocardiography in hypertension and general population research. Hypertension 1987, 9:97-II. 
31. Wallerson DC, Devereux RB: Reproducibility of echocardiographic left ventricular dimensions. Hypertension 1987, 9:6-II.

32. Wong M, Shah PM, Taylor RD: Reproducibility of left ventricular internal dimensions with $M$ mode echocardiography: effects of heart size, body position and transducer angulation. $\mathrm{Am} J$ Cardiol 198I, 47: 1068-1074.

33. Collins HW, Kronenberg MW, Byrd BF 3rd: Reproducibility of left ventricular mass measurements by two-dimensional and $M$ mode echocardiography. J Am Coll Cardiol 1989, 14:672-676.

Publish with Biomed Central and every scientist can read your work free of charge

"BioMed Central will be the most significant development for disseminating the results of biomedical research in our lifetime. " Sir Paul Nurse, Cancer Research UK

Your research papers will be:

- available free of charge to the entire biomedical community

- peer reviewed and published immediately upon acceptance

- cited in PubMed and archived on PubMed Central

- yours - you keep the copyright 